\title{
Subcutaneous Rituximab for the Treatment of B-Cell Hematologic Malignancies: A Review of the Scientific Rationale and Clinical Development
}

\author{
Andrew Davies · Claude Berge $\cdot$ Axel Boehnke $\cdot$ Anjum Dadabhoy \\ Pieternella Lugtenburg · Simon Rule · Mathias Rummel • \\ Christine McIntyre $\cdot$ Rodney Smith $\cdot$ Xavier Badoux
}

Received: July 4, 2017 / Published online: October 5, 2017

(C) The Author(s) 2017. This article is an open access publication

\section{ABSTRACT}

Abstract: Rituximab $\left(\right.$ MabThera $^{\circledR} /$ Rituxan $\left.^{\circledR}\right), \quad$ a chimeric murine/human monoclonal antibody that binds specifically to the transmembrane antigen CD20, was the first therapeutic antibody to enter clinical practice for the treatment of cancer. As monotherapy and in combination with

Enhanced content To view enhanced content for this article go to http://www.medengine.com/Redeem/ AAFBF060596ADEBE.

\section{A. Davies ( $\square)$}

Cancer Research UK Centre, Faculty of Medicine,

University of Southampton, Southampton, UK

e-mail: A.Davies@southampton.ac.uk

C. Berge · A. Boehnke - A. Dadabhoy · R. Smith

F. Hoffmann-La Roche Ltd, Basel, Switzerland

P. Lugtenburg

Department of Haematology, Erasmus MC Cancer

Institute, Rotterdam, The Netherlands

S. Rule

Plymouth University Medical School, Plymouth, UK

M. Rummel

Hospital of the Justus-Liebig-University, Giessen,

Germany

C. McIntyre

Clinical Pharmacology, Roche Products Ltd.,

Welwyn Garden City, UK

X. Badoux

Department of Haematology, St. George Hospital, Kogarah, Australia chemotherapy, rituximab has been shown to prolong progression-free survival and, in some indications overall survival, in patients with various B-cell malignancies, while having a well-established and manageable safety profile and a wide therapeutic window. As a result, rituximab is considered to have revolutionized treatment practices for patients with B-cell malignancies. A subcutaneous (SC) formulation of rituximab has been developed, comprising the same monoclonal antibody as the originally marketed formulation [rituximab concentrate for solution for intravenous (IV) infusion], and has undergone a detailed, sequential clinical development program. This program demonstrated that, at fixed doses, rituximab SC achieves non-inferior serum trough concentrations in patients with non-Hodgkin lymphoma and chronic lymphocytic leukemia, with comparable efficacy and safety relative to the IV formulation. The added benefit of rituximab SC was demonstrated in dedicated studies showing that rituximab SC allows for simplified and shortened drug preparation and administration times resulting in a reduced treatment burden for patients as well as improved resource utilization (efficiency) at the treatment facility. The improved efficiency of delivering rituximab's benefit to patients may broaden patient access to rituximab therapy in areas with low levels of healthcare resources, including IV-chair capacity constraints. This article is a companion paper to G. Salles, et al., which is also published in this issue. 
Funding: F. Hoffmann-La Roche Ltd.

Keywords: Chronic lymphocytic leukemia; Diffuse large B-cell lymphoma; Follicular lymphoma; Intravenous; MabThera ${ }^{\circledR}$; Non-Hodgkin lymphoma; Rituxan ${ }^{\circledR}$; Rituximab; Subcutaneous

\section{INTRODUCTION}

Rituximab (MabThera ${ }^{\circledR} /$ Rituxan $^{\circledR}$ ) was the first therapeutic monoclonal antibody to enter clinical practice for the treatment of cancer. Engineered as a chimeric murine/human monoclonal antibody, rituximab binds specifically to the transmembrane antigen CD20, which is present on the cell surface of pre-B lymphocytes and mature B lymphocytes [1]. Since initial marketing authorization in 1997, rituximab has revolutionized the treatment of patients with B-cell malignancies [cumulative patient-market exposure in hematologic malignancies 1997-2016 was more than 4.4 million patients (Roche data on file)] and is currently standard of care for the common B-cell non-Hodgkin lymphomas (NHLs), follicular lymphoma (FL) and diffuse large B-cell lymphoma (DLBCL), as well as chronic lymphocytic leukemia (CLL) [2-5]. In 2015, rituximab was classified as an essential medicine by the World Health Organization [6].

In $\mathrm{FL}$, rituximab is given in combination with chemotherapy to previously untreated patients $[7,8]$ and forms the backbone of most treatment regimens $[5,9]$. It is also indicated for maintenance therapy in FL and as monotherapy for relapsed/refractory disease [7, 8]. Rituximab is indicated in combination with chemotherapy in first-line DLBCL $[7,8]$, with combinations including cyclophosphamide, doxorubicin, vincristine, and prednisolone (R-CHOP) being the most common initial therapy $[5,10]$.

While FL and DLBCL both arise from B lymphocytes, the two diseases have distinct pathologies, natural histories, prognoses, and standard treatments. FL is an indolent lymphoma that arises from germinal center B cells [9], while DLBCL is an aggressive, heterogeneous lymphoma of large B cells that has a number of molecular subtypes, including the germinal center B-cell (GCB) and activated

B-cell (ABC) types [10]. FL is biologically heterogeneous, with a widely varying prognosis [9], whereas DLBCL typically presents as an aggressive lymphoma that evolves over months and leads to symptomatic disease that would be imminently fatal if left untreated [10]. The majority of patients with DLBCL can be cured with immunochemotherapy, although those failing R-CHOP induction generally succumb to their disease. In the LNH-98.5 trial in 399 patients with DLBCL, 10-year overall survival (OS) was $43.5 \%$ in patients receiving $\mathrm{R}-\mathrm{CHOP}$ and $27.6 \%$ with $\mathrm{CHOP}$ alone [11]. Immunochemotherapy incorporating rituximab is currently also a standard first-line treatment for CLL, a clonal lymphoproliferative disorder of mature, peripheral B lymphocytes [12]. Rituximab in combination with chemotherapy is indicated for the treatment of both previously untreated and relapsed/refractory CLL $[7,8]$.

Numerous investigations have indicated that rituximab's anti-tumor activity is mediated via several mechanisms, including antibody-dependent cellular cytotoxicity, complement-dependent cytotoxicity, induction of apoptosis, and the phagocytosis of opsonized targets by phagocytes, such as macrophages [1, 13-15]. In addition to direct anti-tumor effects, rituximab appears to work in synergy with other chemotherapeutic agents, sensitizing tumor cells to a variety of agents, including paclitaxel, gemcitabine, bendamustine, cladribine, doxorubicin, and mitoxantrone [16-18].

Intravenous (IV) rituximab first gained regulatory approval in 1997 from the US Food and Drug Administration (FDA) and in 1998 from the European Medicines Agency (EMA) for use in relapsed/refractory indolent NHL. Later this approval was extended to include both induction treatment and maintenance treatment of $\mathrm{FL}$, treatment of DLBCL, as well as first-line and relapsed/refractory CLL treatment. Clinical studies supporting these indications have shown that rituximab given as a single agent or added to standard chemotherapy prolongs progression-free survival (PFS) and, in some indications, OS, in a spectrum of B-cell malignancies [19-22], while having a well-established and manageable safety profile [20-22] and a wide therapeutic window [23-26]. 
Rituximab was initially formulated for administration via IV infusion, with infusions typically administered over a period of $1.5-6 \mathrm{~h}$ $[7,27]$. The first infusion is usually the longest, to minimize the risk of infusion-related reactions (IRRs), with subsequent infusions being given at slightly more rapid rates. IRRs are reported by most patients during their first infusion (77\%) [7], but decrease substantially with subsequent infusions, and cytokine release syndrome accompanied by hypotension and bronchospasm is reported in $10 \%$ of patients [7]. In recent years, a 90-min infusion schedule for second and subsequent infusions has proven to be feasible and safe [27].

This review article summarizes the rationale and key studies in the development of rituximab SC. The information reported is derived from previously conducted studies: this does not include any new studies of human or animal subjects performed by any of the authors.

\section{The Need for a Subcutaneous Formulation}

While abbreviated IV infusion schedules can help to reduce the time required to treat each patient, IV infusions per se place a considerable burden on patients and healthcare systems alike, particularly in low- and middle-income countries (LMICs). In these regions, patients have restricted access to the healthcare resources needed to deliver labor-intensive anti-cancer treatments, and less funding is available to provide services and medications than in other areas $[28,29]$.

As such, a rituximab formulation requiring less time and fewer resources to administer would have many advantages for patients and healthcare systems, in both poorer and wealthier countries. Such a formulation could improve access to treatment, particularly where healthcare resources are limited, and could reduce the burden of treatment and help to free up healthcare provider capacity generally. With this in mind, a rituximab SC injection, containing the same active molecule as the standard rituximab IV infusion, was developed. The aim was to simplify and shorten rituximab administration to reduce the treatment burden for patients as well as improve resource utilization at the treatment facility, thereby facilitating more timely and increased access to this important drug in resource-poor settings. Rituximab SC is now approved for use in the EU [March 2014 (NHL), May 2016 (CLL)] and USA (June 2017) for the treatment of patients with NHL and CLL [30-32].

\section{FORMULATION OF SUBCUTANEOUS RITUXIMAB}

\section{Recombinant Human Hyaluronidase}

Establishing the SC route of administration for rituximab was not possible using the existing IV formulation, because the volumes required to achieve therapeutic levels exceed tolerable thresholds [33]. Therefore, a new rituximab formulation was needed to facilitate SC administration. To reduce the injection volume, the SC solution was concentrated 12-fold (to $120 \mathrm{mg} / \mathrm{ml}$ ) relative to the IV formulation $[33,34]$. Even at this concentration, however, the volume required was still prohibitive for SC injection. Rituximab was therefore co-formulated with recombinant human hyaluronidase (rHuPH20), an enzyme used to increase the dispersion and absorption of co-administered substances when given subcutaneously [7]. rHuPH20 achieves this by transiently depolymerizing interstitial hyaluronan at the injection site, resulting in decreased resistance to fluid flow and increased dispersion and absorption of injected medicines and fluids, and allowing the injection of volumes which would otherwise be too large for SC administration with limited swelling or pain [35]. rHuPH20 is long established as a permeating agent in palliative care, with rapid and localized action, no systemic distribution and no long-term effects on tissue [36]. rHuPH20 has been shown to be well tolerated, with no allergic reactions occurring in healthy volunteers who were injected intradermally [37]. Furthermore, no interactions between rituximab and $\mathrm{rHuPH} 20$ in the rituximab SC drug product were identified during the development program (Roche Data on File). 


\section{Scientific Rationale}

The rituximab SC development program was founded on the knowledge and experience accumulated with rituximab in clinical practice and based on the scientific consideration that serum rituximab levels at least as high as those achieved after IV infusion would result in at least the same degree of target-site saturation and, as a result, provide the same degree of efficacy, regardless of the administration route $[34,38]$. Therefore, a pharmacokinetic (PK)-based clinical bridging program was undertaken, aimed at achieving PK non-inferiority of rituximab SC relative to the established IV dosing regimens for NHL and CLL and evaluating whether a change in administration route has an impact on the anti-B-cell activity and safety profile of rituximab in the treatment of FL, DLBCL, and CLL. Based on the fact that the monoclonal antibody in both rituximab formulations was identical, the development program aimed to demonstrate PK non-inferiority of rituximab SC relative to rituximab IV and provide supportive evidence of comparable clinical outcomes to validate the PK-bridging approach and support extrapolation to the full range of oncology indications established for rituximab.

\section{Pharmacokinetic Considerations}

The primary PK endpoint used in clinical bridging was the rituximab serum trough concentration $\left(C_{\text {trough }}\right) . C_{\text {trough }}$ was selected as the most appropriate measure of exposure to bridge rituximab IV to SC because it reflects the minimum concentration of rituximab during a respective dosing interval, which is available for binding to the target and therefore can be used as a reference to maintain target saturation of $B$ cells to achieve the desired pharmacodynamic (PD) effect and clinical efficacy. By ensuring non-inferior serum rituximab $C_{\text {trough }}$ after SC injection relative to IV administration, target-receptor occupancy would be maintained and therefore the same degree of anti-B-cell activity was expected.
AUC was chosen as the secondary PK endpoint because this parameter provides information on exposure during the entire treatment cycle and, like $C_{\text {trough, }}$, correlates with response $[39,40] . C_{\max }$ was not considered an appropriate PK parameter when comparing the IV and SC routes of administration since the inherent kinetics are different: $C_{\max }$ via the IV route is instantaneous at the end of the infusion and is an arbitrary measure before equilibration occurs between the different blood, tissue, and lymphatic compartments, whereas $C_{\max }$ via the SC route is achieved in approximately 3 days $[7,8]$, i.e., there is additional time in which target-specific elimination [41] could potentially affect $C_{\text {max }}$. The fact that target-specific elimination does not affect $C_{\max }$ after IV infusion may also explain why $C_{\max }$ does not correlate with response [39].

In developing a new dosage form of rituximab for SC administration, a switch from body surface area (BSA)-adjusted dosing to fixed (flat) dosing was considered to simplify drug preparation (ready-to-use formulation, reducing wastage) and to reduce the potential risk of dosing errors. The use of body-size-adjusted dosing in oncology is largely historical and based on many years of experience with chemotherapeutic agents that have a narrow therapeutic window. However, monoclonal antibodies such as rituximab (the first to be approved for treatment of lymphoma) have a wide therapeutic window, and therefore it is possible to adopt a different approach. Fixed dosing was explored for rituximab SC based on a published simulation study of 12 monoclonal antibodies including rituximab, which showed that the variability in PK would be no greater with a fixed-dose approach than with a body-size-adjusted dosing approach [42].

In moving from BSA-adjusted dosing with rituximab IV to fixed dosing with rituximab SC, differences in exposure were expected across the treated population, with a trend toward a relatively lower exposure in patients with a high BSA and a relatively higher exposure in patients with a low BSA. Consequently, the selected fixed dose of rituximab SC needed to be high enough to provide sufficient drug exposure over the entire BSA range to ensure clinical benefit in 
patients with high BSA, while maintaining an acceptable safety profile in patients with low BSA. Given the wide therapeutic window of rituximab, it was considered unlikely that differences in exposure expected after SC administration compared with IV administration would result in a greater risk of adverse reactions.

\section{PRE-CLINICAL STUDIES}

Initial studies comparing the IV and SC formulations of rituximab were conducted in mice [34] and cynomolgus monkeys [43]. These investigations provided the first evidence that rituximab SC had similar PK, PD, and anti-tumor activity to the IV formulation. A human tumor xenograft model (severe combined immunodeficiency mice transplanted with the Z138 mantle cell lymphoma cell line) showed similar $C_{\text {trough }}$ values and a comparable reduction in tumor size across three dose levels of rituximab SC and IV [34]. In cynomolgus monkeys, comparable $C_{\text {trough }}$ concentrations were achieved following rituximab IV and SC administration; this was accompanied by equivalent PD effects (i.e., target B-cell depletion in the peripheral circulation and distant lymph nodes) [43]. Subsequently, similar PD

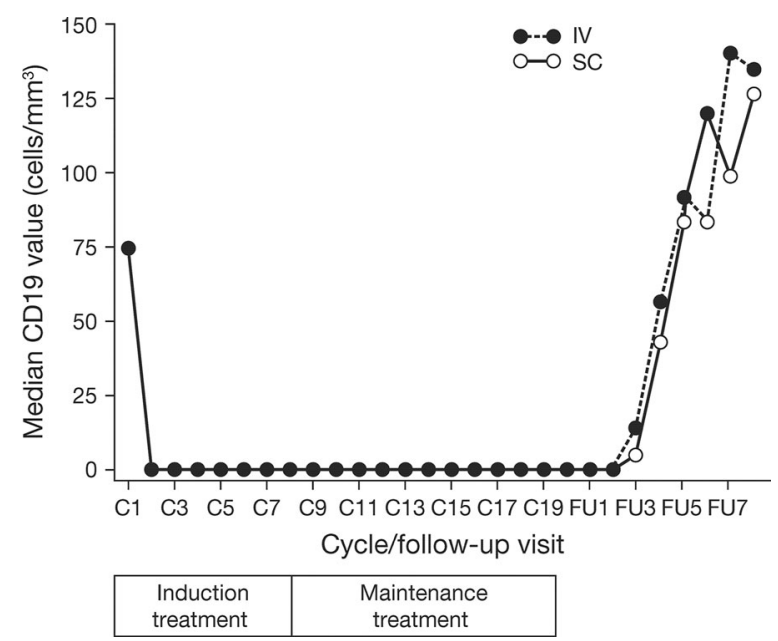

Fig. 1 Time-time curve of B-cell depletion in SABRINA [44, data on file] effects were seen in the SABRINA study (Fig. 1, 44).

\section{CLINICAL STUDIES}

A stepwise approach was adopted to select and confirm the rituximab SC doses in NHL and CLL across the three PK-bridging clinical development studies in terms of non-inferior $C_{\text {trough }}$ relative to rituximab IV and to investigate the effect of the administration route on the anti B-cell activity and safety profile of rituximab (Fig. 2; Table 1).

\section{Pharmacokinetic Studies: Dose Finding}

\section{Non-Hodgkin Lymphoma}

The first clinical study conducted using the new SC formulation of rituximab was the phase $\mathrm{Ib}$ SparkThera study (Table 1), [45]. SparkThera investigated the PK, safety, and tolerability of rituximab SC in patients with FL. The two-part study was conducted in the FL maintenance setting following an adequate response to induction therapy and at least one cycle of rituximab IV monotherapy in maintenance. Patients were thus harmonized by the fact that they had all achieved at least a partial response (PR) to rituximab-containing induction therapy (with or without chemotherapy). The patients' low tumor burden and B-cell-depleted status upon entering the study made them an optimal population for the study of PK parameters with minimal effects of target-specific rituximab elimination, which could potentially confound comparison of the PK profiles of the different routes of administration. PK variability was expected to be low, resulting in a patient population with adequate homogeneity to investigate the PK parameters of rituximab administered either directly into the systemic circulation (IV) or via absorption from the SC tissue.

The objective of the SparkThera study was to determine a SC dose that would yield a rituximab $C_{\text {trough }}$ concentration in the same range as that achieved with rituximab IV at the standard dose of $375 \mathrm{mg} / \mathrm{m}^{2}$ across the clinically established dosing intervals as well as to select a 


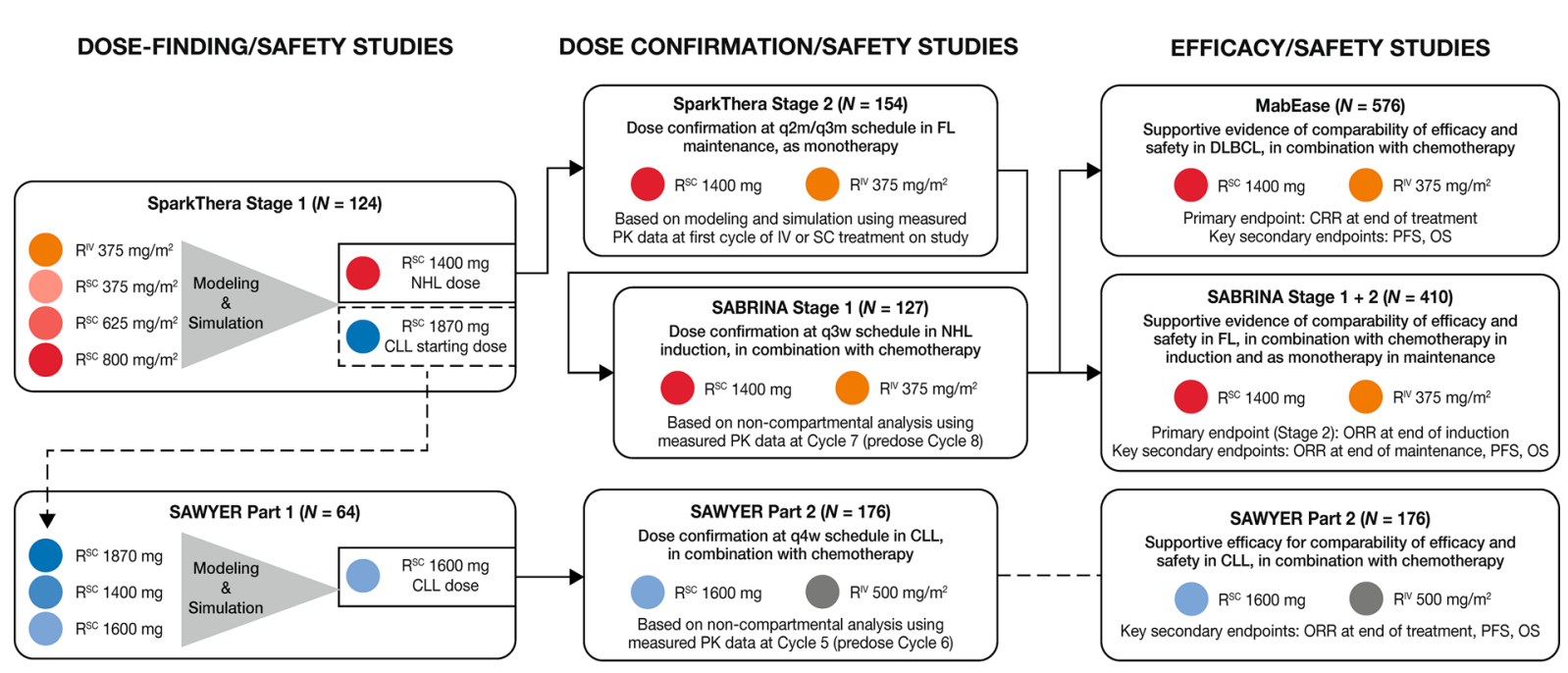

PATIENT PREFERENCE/SAFETY STUDY

Fig. 2 Overview of the clinical development of rituximab. $S C$ dose-finding/confirmation and efficacy studies, $A U C$ area under the concentration-time curve, $C I$ confidence interval, $C R R$ complete response $(\mathrm{CR} / \mathrm{CRu})$ rate; $C_{\text {trough }}$, trough or minimum serum concentration, CTSQ cancer

starting dose for the CLL dose-finding part of the SAWYER study (see below). Patients with FL who had achieved at least a PR following rituximab-based induction therapy, and had received at least one dose of IV rituximab as maintenance therapy, were given a single dose of either rituximab SC $\left(375,625\right.$, or $\left.800 \mathrm{mg} / \mathrm{m}^{2}\right)$ or rituximab IV $\left(375 \mathrm{mg} / \mathrm{m}^{2}\right)$ as part of their maintenance therapy schedule. After the single dose, all patients continued with rituximab IV until they had completed 2 years of maintenance. PK modeling based on data from stage 1 was then used to determine a fixed dose of rituximab SC that would result in non-inferior $C_{\text {trough }}$ and comparable AUC to that achieved with rituximab IV at $375 \mathrm{mg} / \mathrm{m}^{2}$, regardless of BSA and whether rituximab was given every 2 or 3 months. A dose of $1400 \mathrm{mg}$ was selected for assessment in stage 2 to ensure that all patients, including those at the upper end of the BSA range, would achieve sufficiently high $C_{\text {trough }}$ levels so that under-dosing did not occur. treatment satisfaction questionnaire, GMR geometric mean ratio, $I N V$ investigator, $I R C$ independent review committee, $O R R$ overall response rate, $P P Q$ patient preference questionnaire, $R A S Q$ rituximab administration satisfaction questionnaire

\section{Chronic Lymphocytic Leukemia}

The first study of rituximab SC in patients with CLL was the phase $1 \mathrm{~b}$, two-part SAWYER study [46]. In the dose-finding stage, patients with previously untreated CLL received five cycles of rituximab IV in combination with fludarabine and cyclophosphamide (FC), followed by a single dose of rituximab SC given at one of three dosing levels: 1870 (initially predicted by data from the SparkThera trial), 1400, or $1600 \mathrm{mg}$. As in SparkThera, the primary objective of this stage was to identify a fixed SC dose that would achieve comparable rituximab $C_{\text {trough }}$ levels to those achieved with the established IV dose (500 mg/ $\mathrm{m}^{2}$, 4 weekly). The resulting PK data were applied to a population PK model, which predicted that a fixed SC dose of $1600 \mathrm{mg}$ would achieve non-inferior $C_{\text {trough }}$ values to 4 -weekly rituximab IV at $500 \mathrm{mg} / \mathrm{m}^{2}$ (i.e., the clinically established rituximab dose and dosing interval for CLL). 


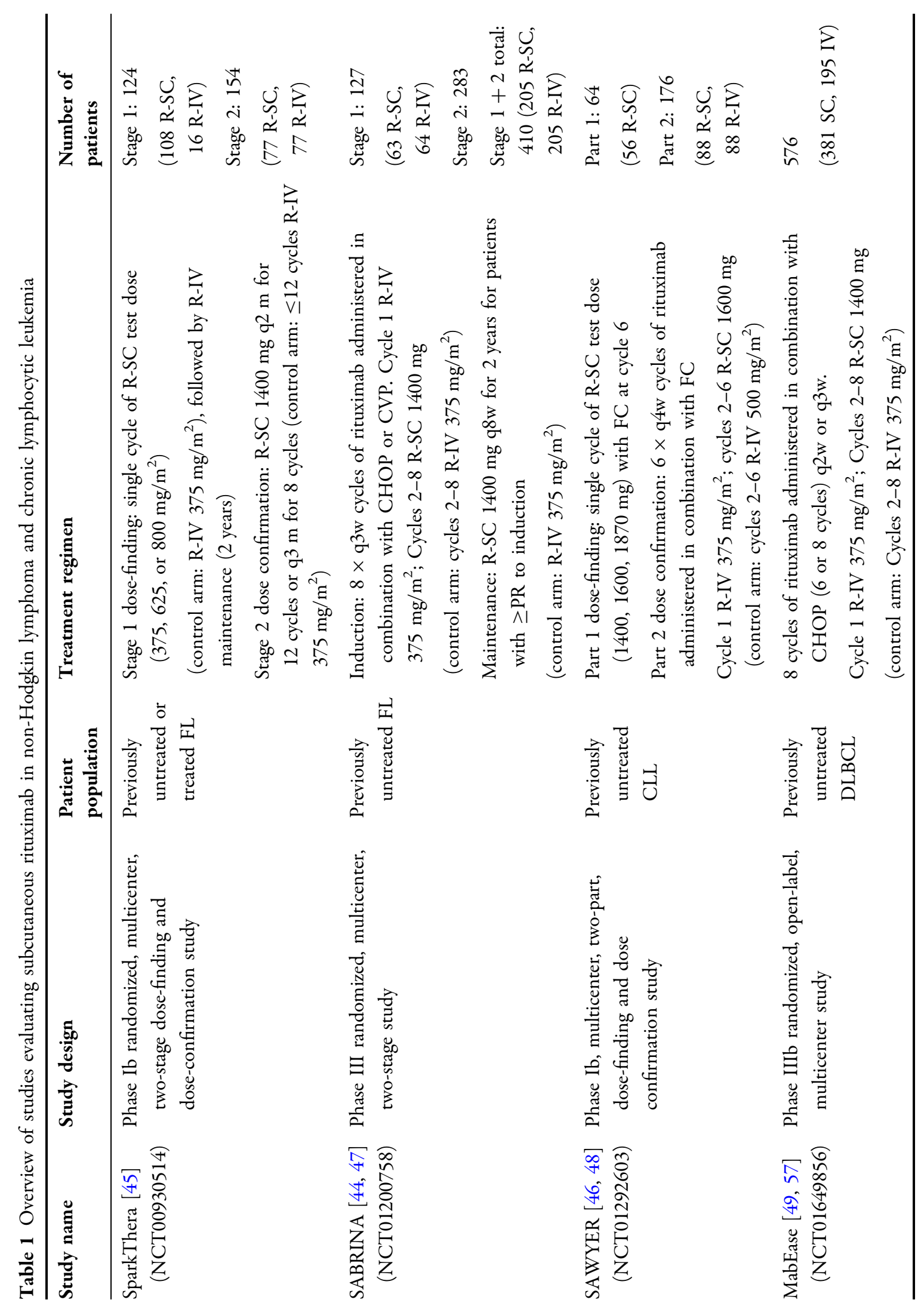




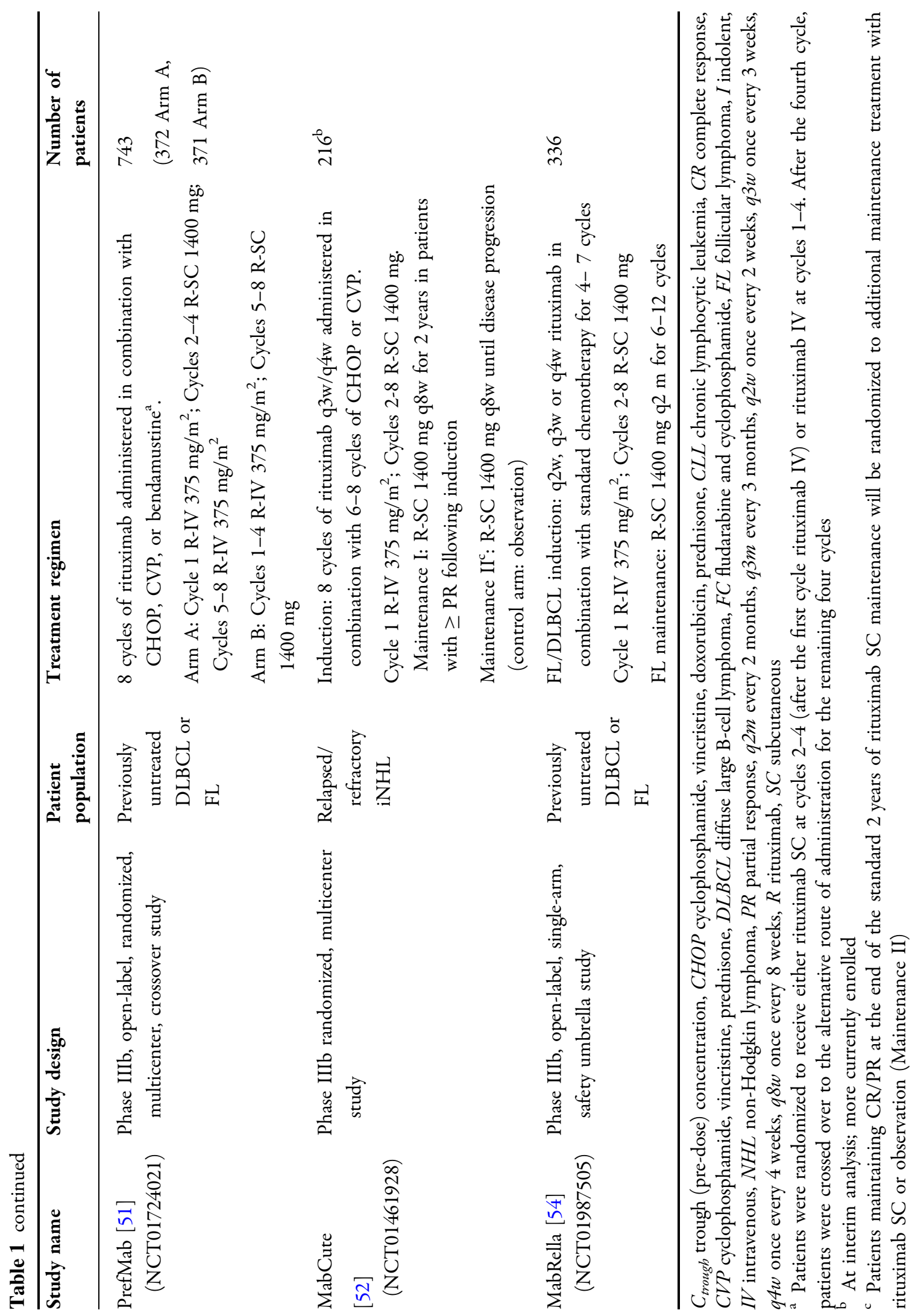




\section{Pharmacokinetic Studies: Dose Confirmation}

\section{Non-Hodgkin Lymphoma}

Two studies in patients with NHL confirmed $C_{\text {trough }}$ non-inferiority for rituximab SC at the chosen fixed dose relative to the standard rituximab IV dose: SparkThera stage 2 and SABRINA stage 1. In SparkThera stage 2, 154 additional patients who had achieved at least PR following induction and had received at least one dose of rituximab IV as monotherapy in maintenance were randomized to receive either the fixed $1400 \mathrm{mg}$ SC dose determined using data from stage 1 or the standard rituximab IV dose of $375 \mathrm{mg} / \mathrm{m}^{2}$, both given at 2- or 3-month intervals until 2 years of maintenance had been completed [45]. The study confirmed that $C_{\text {trough }}$ levels following a fixed SC dose of $1400 \mathrm{mg}$ rituximab were non-inferior to the $C_{\text {trough }}$ levels achieved with rituximab IV at $375 \mathrm{mg} / \mathrm{m}^{2}$, when given at either 2- or 3-month intervals [Table 2].

SABRINA was a two-stage randomized, open-label, phase III study of rituximab given in combination with either cyclophosphamide, vincristine and prednisone (CVP) or CHOP chemotherapy to previously untreated patients with FL. Patients received one induction dose of rituximab IV, followed by either SC (1400 mg) or IV $\left(375 \mathrm{mg} / \mathrm{m}^{2}\right)$ rituximab once every 3 weeks at cycles 2-8 [44, 47]. Patients with a complete response (CR) or PR following induction therapy continued IV or SC maintenance rituximab every 8 weeks. The primary endpoint assessed for stage 1 was the ratio of observed rituximab $C_{\text {trough }}$ between the SC and IV groups at induction cycle 7 (i.e., before dosing cycle 8). The last $C_{\text {trough }}$ value of the induction dosing interval was chosen to minimize the effects of target-specific elimination of rituximab when assessing the effects of a change in administration route on PK. At the end of induction cycle 7 , the geometric mean for rituximab $C_{\text {trough }}$ was higher in the SC group than in the IV group (Table 2), and the lower limit for the two-sided $90 \%$ confidence interval of the SC to IV geometric mean ratios exceeded the prespecified margin of 0.8 , confirming $C_{\text {trough }}$ non-inferiority of rituximab SC to IV.

\section{Chronic Lymphocytic Leukemia}

In part 2 of the SAWYER study, a separate group of previously untreated patients with CLL received induction treatment with $\mathrm{FC}$, plus either a fixed $1600 \mathrm{mg}$ dose of rituximab SC or $500 \mathrm{mg} / \mathrm{m}^{2}$ rituximab IV every 4 weeks for up to six cycles [48]. In cycle 1 , all patients received rituximab IV at $375 \mathrm{mg} / \mathrm{m}^{2}$. At the end of cycle 5 , the geometric mean $C_{\text {trough }}$ in patients given rituximab SC was non-inferior to that in patients given rituximab IV (Table 2), thus confirming non-inferiority of the chosen SC dose relative to the standard IV dose. In addition, AUC data at cycle 6 indicated that exposure was at least as high after rituximab SC as after IV dosing (Table 2).

Notably, the high BSA subgroup in the SAWYER study had mean $C_{\text {trough }}$ and AUC values after administration of rituximab SC that were at least as high as those following IV administration of rituximab, a finding that was also replicated in NHL patients with high BSA in the SABRINA [47] and SparkThera studies [45]. Together these findings demonstrate that the selected doses of rituximab SC 1400 and $1600 \mathrm{mg}$ for NHL and CLL, respectively, result in adequate exposure across all BSA subgroups and at least the same exposure compared with the standard rituximab IV doses and dosing intervals in these settings.

\section{Clinical Studies Confirming the Efficacy of Subcutaneous Rituximab}

\section{Non-Hodgkin Lymphoma}

Two large phase III studies, SABRINA and MabEase, were conducted to investigate whether SC administration impacts the anti-lymphoma activity of rituximab (Fig. 2) [44, 47, 49].

After stage 1 had confirmed the $C_{\text {trough }}$ non-inferiority of rituximab SC, stage 2 of the SABRINA study enrolled 283 additional patients who were randomized to the same treatment and schedules as in stage 1 (Table 1 ). The objectives of stage 2 included providing additional efficacy data and estimating response rates at the end of induction [44]. In the pre-planned pooled analysis, the overall response (OR) rate at the end of induction was 
Table 2 Summary of $C_{\text {trough }}$ and AUC data from pharmacokinetic analyses in the SparkThera (follicular lymphoma), SABRINA (non-Hodgkin lymphoma), and SAWYER (chronic lymphocytic leukemia) studies $[44,45,47,48]$

\begin{tabular}{|c|c|c|c|}
\hline \multicolumn{4}{|l|}{$C_{\text {trough }}$ data } \\
\hline \multirow[t]{2}{*}{$\begin{array}{l}\text { Study (rituximab dose) } \\
\text { [dosing frequency/sampling time] }\end{array}$} & \multicolumn{2}{|c|}{$\begin{array}{l}\text { Rituximab } C_{\text {trough }}(\mu \mathrm{g} / \mathrm{ml}) \\
\text { Geometric mean }[95 \% \mathrm{CI}]\end{array}$} & \multirow[t]{2}{*}{$\begin{array}{l}\text { Geometric mean ratio } \\
C_{\text {trough(SC) }} / C_{\text {trough(IV) }}[90 \% \mathrm{CI}]\end{array}$} \\
\hline & SC & IV & \\
\hline SparkThera (all SC doses; $375 \mathrm{mg} / \mathrm{m}^{2}$ IV) & $32.2^{\mathrm{a}}$ & $25.9^{\mathrm{a}}$ & 1.24 \\
\hline [q2 m/maintenance cycle 2] & {$[28.0-37.1]$} & {$[21.5-31.3]$} & {$[1.02-1.51]$} \\
\hline SparkThera (all SC doses; $375 \mathrm{mg} / \mathrm{m}^{2}$ IV) & $12.1^{\mathrm{a}}$ & $10.9^{\mathrm{a}}$ & 1.12 \\
\hline [q3 m/maintenance cycle 2] & {$[10.1-14.6]$} & {$[8.4-14.1]$} & {$[0.86-1.45]$} \\
\hline \multicolumn{4}{|l|}{ SABRINA (1400 mg SC; $375 \mathrm{mg} / \mathrm{m}^{2} \mathrm{IV}$ ) } \\
\hline \multicolumn{4}{|l|}{ [q3w/induction cycle 7$]$} \\
\hline \multirow[t]{2}{*}{ Stage 1} & 134.6 & 83.1 & $1.62^{\mathrm{c}}$ \\
\hline & {$\left[43.2 \%^{\mathrm{b}}\right]$} & {$\left[36.7 \%^{\mathrm{b}}\right]$} & {$[1.36-1.94]$} \\
\hline Stage 2 & - & - & $1.5[1.3-1.7]$ \\
\hline Pooled & 121 & 78 & $1.5[1.4-1.7]$ \\
\hline SAWYER (1600 mg SC; $\left.500 \mathrm{mg} / \mathrm{m}^{2} \mathrm{IV}\right)$ & 97.5 & 61.5 & 1.53 \\
\hline [q4w/induction cycle 5] & & & {$[1.27-1.85]$} \\
\hline
\end{tabular}

\begin{tabular}{|c|c|c|c|}
\hline \multicolumn{4}{|l|}{ AUC data } \\
\hline \multirow{2}{*}{$\begin{array}{l}\text { Study (rituximab dose) } \\
\text { [dosing frequency/sampling time] }\end{array}$} & \multicolumn{2}{|c|}{$\begin{array}{l}\text { Rituximab AUC, } \mu \mathrm{g} \cdot \mathrm{day} / \mathrm{ml} \\
\text { Geometric mean }[95 \% \mathrm{CI}]\end{array}$} & \multirow{2}{*}{$\begin{array}{l}\text { Geometric mean ratio } \\
\mathrm{AUC}_{(\mathrm{SC})} / \mathrm{AUC}_{(\mathrm{IV})}[90 \% \mathrm{CI}]\end{array}$} \\
\hline & SC & IV & \\
\hline SparkThera (all SC doses; $375 \mathrm{mg} / \mathrm{m}^{2} \mathrm{IV}$ ) & $5430^{\mathrm{a}}$ & $4012^{\mathrm{a}}$ & $1.35^{\mathrm{d}}$ \\
\hline [q2 m/maintenance cycle 2] & {$[4980-5921]$} & [3721-4326] & {$[1.23-1.49]$} \\
\hline SparkThera (all SC doses; $375 \mathrm{mg} / \mathrm{m}^{2} \mathrm{IV}$ ) & $5320^{\mathrm{a}}$ & $3947^{\mathrm{a}}$ & $1.35^{\mathrm{d}}$ \\
\hline [q3 m/maintenance cycle 2 ] & {$[4880-5799]$} & {$[3662-4255]$} & {$[1.23-1.48]$} \\
\hline SABRINA (1400 mg SC; $375 \mathrm{mg} / \mathrm{m}^{2} \mathrm{IV}$ ) & 3779 & 2734 & $1.38^{\mathrm{c}}$ \\
\hline [q3w/induction cycle 7] & & & {$[1.24-1.53]$} \\
\hline SAWYER (1600 mg SC; $\left.500 \mathrm{mg} / \mathrm{m}^{2} \mathrm{IV}\right)$ & 4089 & 3630 & 1.10 \\
\hline [q4w/induction cycle 6] & & & {$[0.98-1.24]$} \\
\hline
\end{tabular}

$A U C$ area under the concentration-time curve, $C I$ confidence intervals, $C_{\text {trough }}$ trough serum concentration, $I V$ intravenous, $q 2 m$ every 2 months, $q 3 m$ every 3 months, $q 3 w$ every 3 weeks, $q 4 w$ every 4 weeks, $S C$ subcutaneous

${ }^{a}$ Predicted

b Coefficient of variation

c Geometric mean ratio adjusted for tumor load at baseline

d AUC over the dosing interval tau

$84.4 \%$ in the rituximab SC group and $84.9 \%$ in the IV group (Table 3), while CR/unconfirmed CR (CRu) rates were $32.2 \%$ for rituximab SC and
$32.2 \%$ for rituximab IV. ORR at the end of maintenance was $77.9 \% \quad[95 \%$ confidence interval (CI) 71.0-83.9] in the SC group and 
Table 3 Summary of response rates (investigator-assessed; intent-to-treat population) from SABRINA (follicular lymphoma), MabEase (diffuse large B-cell lymphoma), and SAWYER (chronic lymphocytic leukemia) studies $[44,48]$

\begin{tabular}{|c|c|c|c|c|c|}
\hline \multirow[t]{2}{*}{ Study } & \multirow[t]{2}{*}{ Treatment group } & \multirow[t]{2}{*}{$n$} & \multicolumn{3}{|c|}{ Response rate (\%) $\left(95 \% \mathrm{CI}^{\mathrm{a}}\right)$} \\
\hline & & & Complete $^{b}$ & Partial & Overall \\
\hline \multirow[t]{2}{*}{ SABRINA $^{c}$} & $\mathrm{R}(\mathrm{SC})+$ chemo & 205 & $32(26-39)$ & $52(45-59)$ & $84(79-89)$ \\
\hline & $\mathrm{R}(\mathrm{IV})+$ chemo & 205 & $32(26-39)$ & $53(46-60)$ & $85(79-90)$ \\
\hline \multirow[t]{2}{*}{ MabEase $^{c}$} & $\mathrm{R}(\mathrm{SC})+\mathrm{CHOP}$ & 342 & $51(45-56)$ & $32(27-37)$ & $82(78-86)$ \\
\hline & $\mathrm{R}(\mathrm{IV})+\mathrm{CHOP}$ & 177 & $42(35-50)$ & $36(29-43)$ & $78(71-84)$ \\
\hline \multirow[t]{2}{*}{ SAWYER Part $2^{\mathrm{d}}$} & $\mathrm{R}(\mathrm{SC})+\mathrm{FC}$ & 88 & $26(17-37)$ & $59(48-70)$ & $85(76-92)$ \\
\hline & $\mathrm{R}(\mathrm{IV})+\mathrm{FC}$ & 88 & $33(23-44)$ & $48(37-59)$ & $81(71-88)$ \\
\hline
\end{tabular}

CHOP cyclophosphamide, doxorubicin, vincristine, prednisolone, $F C$ fludarabine and cyclophosphamide, $I V$ intravenous, $R$ rituximab, $S C$ subcutaneous

${ }^{a}$ Where available

${ }^{b}$ Includes complete response confirmed and complete response unconfirmed

${ }^{c}$ Response rates at end of induction

${ }^{\mathrm{d}}$ Response rates 3 months after treatment completion

78.1\% (95\% CI 71.3-83.9) in the IV group [44]. Response rates were also comparable across patient subgroups, including gender and body surface area (Fig. 3). At a median follow-up of 37 months, there was no substantial difference between rituximab SC and IV in terms of PFS [hazard ratio (HR) $0.84,95 \%$ CI $0.57-1.23$ ] (Fig. 4a), event-free survival (HR 0.91, 95\% CI $0.64-1.31$ ), or OS (HR 0.81, 95\% CI 0.42-1.57). Furthermore, the stage 1 and 2 pooled geometric mean $C_{\text {trough }}$ data were consistent with the SABRINA and SparkThera stage 1 results and indicate that the subcutaneous dose of $1400 \mathrm{mg}$ rituximab is non-inferior to a $375 \mathrm{mg} / \mathrm{m}^{2}$ intravenous dose of rituximab over the entire treatment course during the induction phase when given every 3 weeks in combination with chemotherapy and during single agent treatment every 2 months for a duration of 2 years (Fig. 4b).

The open-label MabEase study examined whether there were any major efficacy differences between rituximab SC and IV in DLBCL. Patients with previously untreated DLBCL were randomized to receive one cycle of rituximab IV $375 \mathrm{mg} / \mathrm{m}^{2}$ followed by an additional seven cycles of either $1400 \mathrm{mg}$ rituximab SC or $375 \mathrm{mg} / \mathrm{m}^{2}$ rituximab IV, plus six or eight cycles of CHOP every 14 or 21 days (Table 1), [49]. The
$\mathrm{CR} / \mathrm{CRu}$ rate at the end of induction treatment for the intent-to-treat (ITT) population was similar for the two treatment groups (51\% vs. $42 \%$ for rituximab SC vs. rituximab IV, respectively) (Table 3). After a median follow-up of 35 months, median survival in the ITT population was not reached for PFS, EFS, or OS [49].

\section{Chronic Lymphocytic Leukemia}

The secondary endpoint of clinical response in the SAWYER study (stage 2) indicated similar response rates between the rituximab SC and IV treatment groups, which supports the findings in NHL. OR rates 3 months after treatment completion were $85 \%$ and $81 \%$ for the rituximab SC and IV groups, respectively. CR rates were $26 \%$ and $33 \%$ [48].

In summary, given the established $C_{\text {trough }}$ non-inferiority of rituximab SC, the efficacy results of the SABRINA, MabEase, and SAWYER studies consistently demonstrate that switching to the SC route of administration does not impair the anti-B-cell activity of rituximab.

\section{Safety and Tolerability of Subcutaneous Administration}

Rituximab IV is generally well tolerated with a well-defined safety profile [50]. The most 


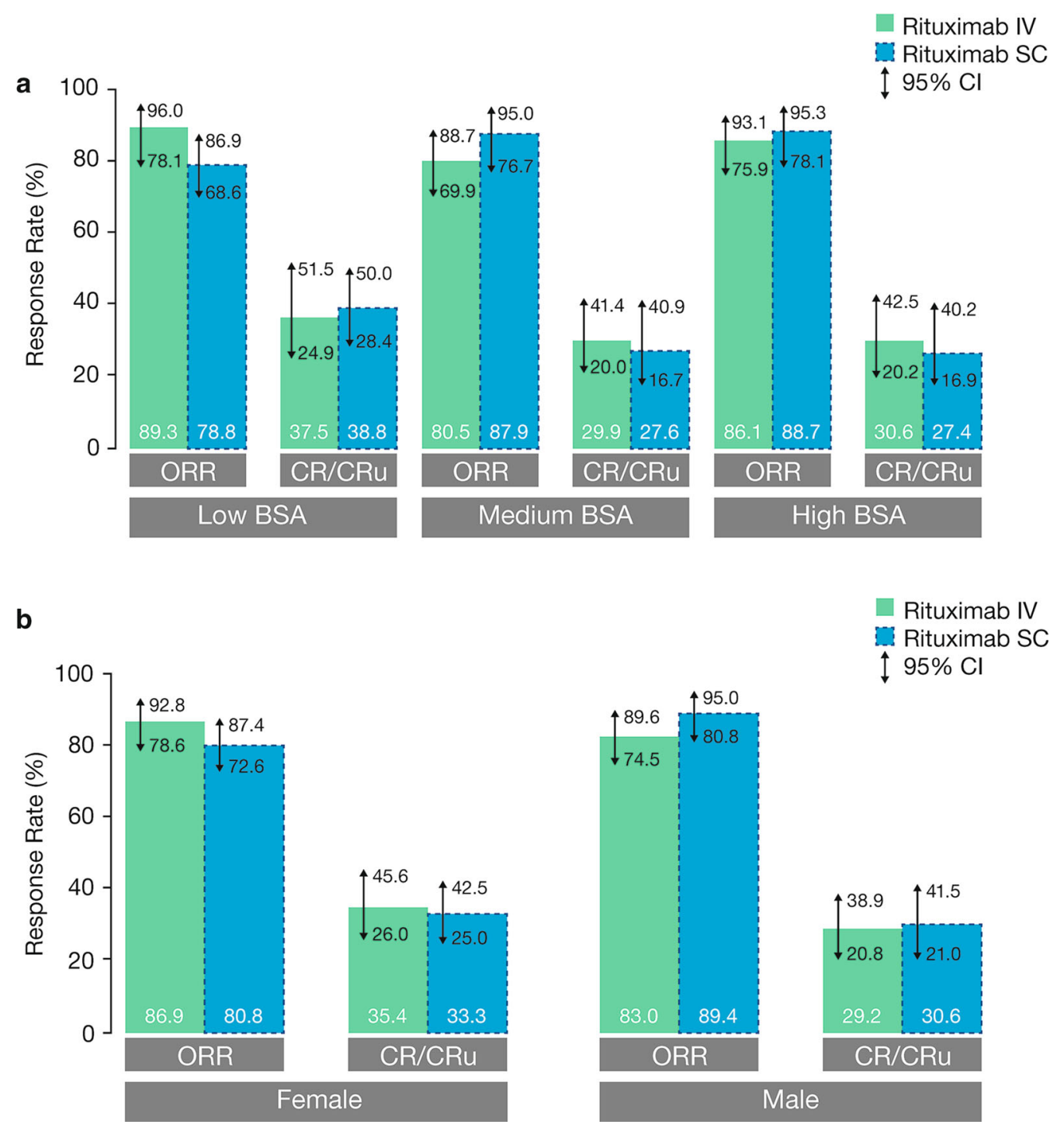

Fig. 3 OR rate by BSA category (a) [Adapted from Davies et al. 2017] [44] and gender (b) [67] at the end of induction in SABRINA. $C I$ confidence interval, $C R$ complete response, $B S A$ body surface area, $I V$ intravenous, $S C$ subcutaneous Part A reproduced from The Lancet Haematology, vol. 4, Davies A, Merli F, Mihaljević B, et al.

common adverse events in patients treated with rituximab IV are infusion-related reactions, including cytokine release syndrome and tumor lysis syndrome, and general hypersensitivity reactions such as fever, chills, rigors, hypotension, urticaria, and angioedema [7]. These are reported by the majority of patients during their first infusion [7], but decrease substantially with subsequent infusions. Notably, in the clinical

Efficacy and safety of subcutaneous rituximab versus intravenous rituximab for first-line treatment of follicular lymphoma (SABRINA): a randomised, open-label, phase 3 trial, e272-82, Copyright (2017), with permission from Elsevier

development studies, rituximab was always administered IV during the first treatment cycle to maintain the option of slowing down or stopping the infusion in case of the development of IRRs. Other common adverse events associated with rituximab include pruritus, nausea, vomiting, headaches, fever, neutropenia, and infections. 


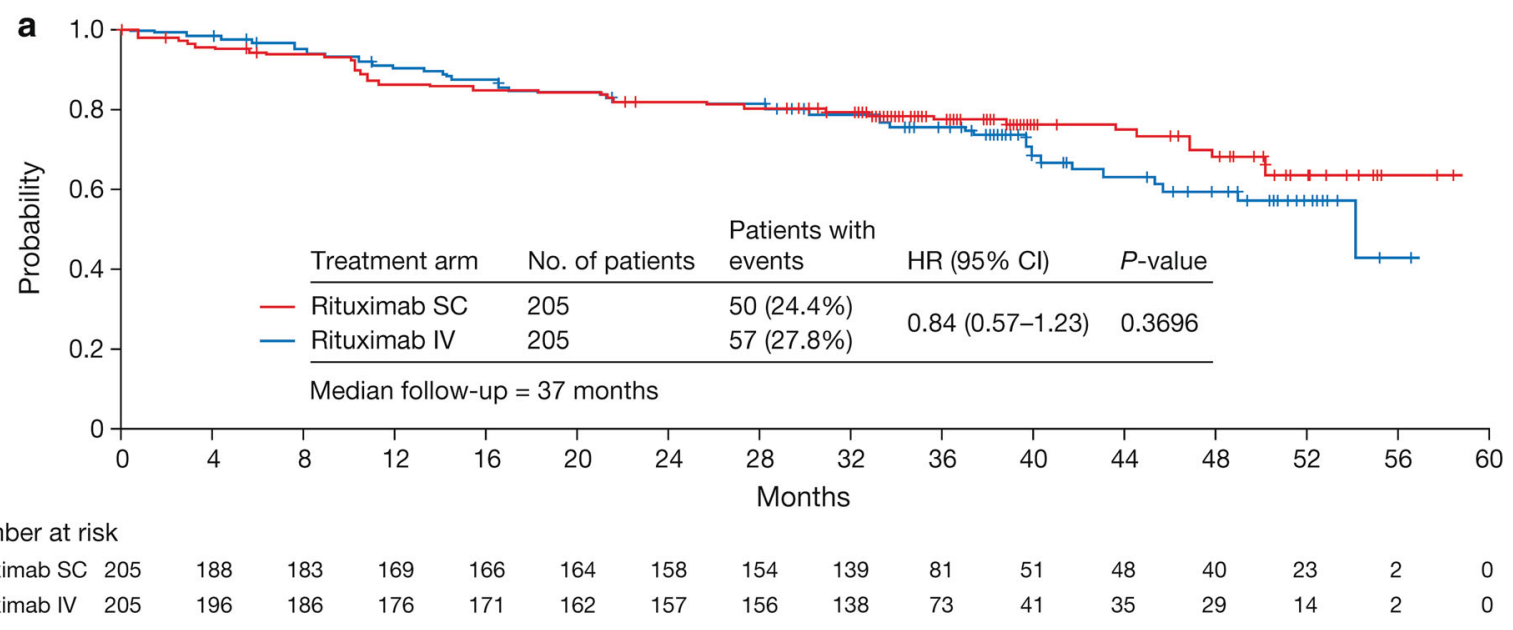

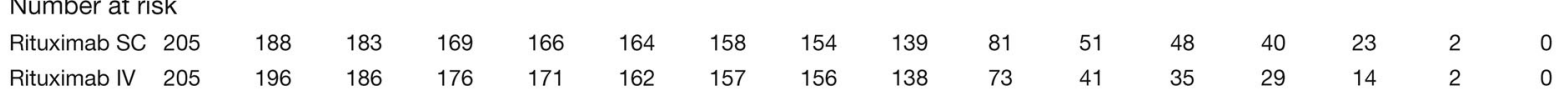

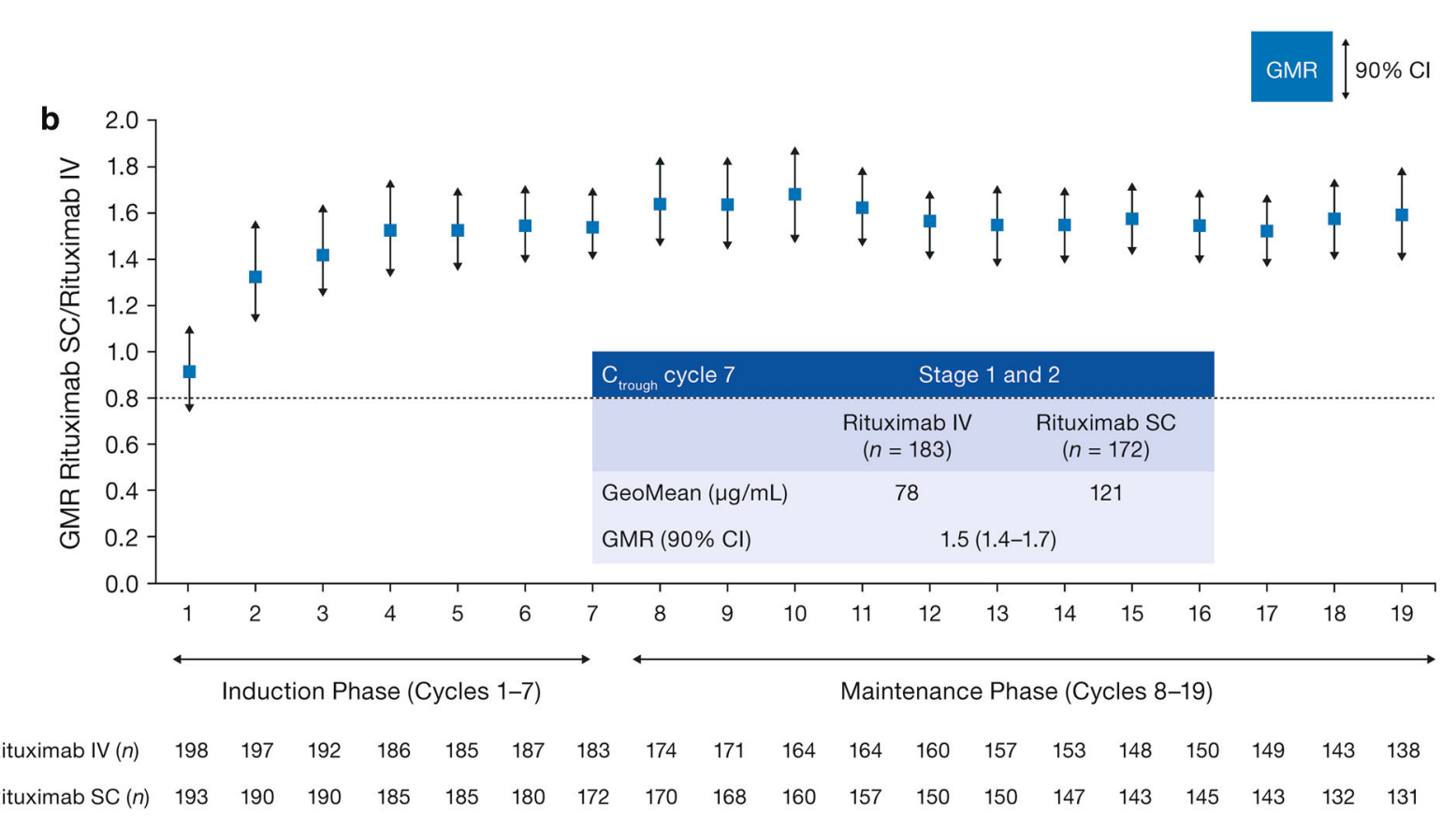

Fig. 4 Progression-free survival in patients receiving rituximab SC or IV in a the phase III SABRINA study [44]. b Geometric mean ratio non-inferiority of rituximab SC versus IV in SABRINA. $C I$ confidence interval, $H R$ hazard ratio. For time-to-event analyses, a hazard ratio below 1 implies a risk reduction for rituximab SC. Reproduced

In the SC clinical development program in over 1500 patients, rituximab SC was well tolerated with an overall safety profile similar to that of the IV formulation and no unexpected safety signals. The adverse events reported for rituximab SC were similar to those reported from The Lancet Haematology, Vol. 4, Davies A, Merli F, Mihaljević B, et al. Efficacy and safety of subcutaneous rituximab versus intravenous rituximab for first-line treatment of follicular lymphoma (SABRINA): a randomised, open-label, phase 3 trial, e272-82, Copyright (2017), with permission from Elsevier

with rituximab IV, with the exception of an increase in the incidence of mostly mild-to-moderate administration-related reactions (ARRs) and local cutaneous reactions reflecting the expected safety profile of subcutaneously administered drugs [44, 45, 48-52]. 
Furthermore, as with the IV formulation, the frequency and intensity of SC-related ARRs decreased with subsequent rituximab SC administration. In a recent retrospective review of case notes (51 patients) from a single institution, rituximab SC was safely administered without antipyretic/antihistamine pre-medication. Among 307 doses of rituximab SC (patients had previously received rituximab IV cycle 1 with prophylaxis as specified in the prescribing information), two adverse events were noted, local skin reaction $(n=1)$ and myalgia $(n=1)$ [53].

In the SABRINA study, where rituximab was administered in combination with chemotherapy, 96\% (rituximab SC) and 95\% (rituximab IV) of patients experienced an adverse event, respectively [44]. Grade $\geq 3$ adverse events occurred in a similar proportion of patients (SC: 56\%; IV: 55\%). The most common any-grade adverse events were (SC vs. IV) neutropenia ( $32 \%$ vs. $27 \%)$, nausea ( $31 \%$ vs. $22 \%)$, constipation (25\% vs. $26 \%)$, cough (23\% vs. $13 \%)$, fatigue $(20 \%$ vs. $18 \%)$, diarrhea (18\% vs. $16 \%)$, asthenia (17\% vs. $13 \%)$, paresthesia (16\% vs. $12 \%)$, pyrexia (15\% vs. $16 \%)$, anemia (15\% vs. $13 \%)$, and upper respiratory tract infection ( $15 \%$ vs. $10 \%)$. Neutropenia (26\% vs. $21 \%$ ) was the most common grade $\geq 3$ adverse event.

Similar grade $\geq 3$ ( $58 \%$ SC vs. $54 \%$ IV) adverse event rates were reported in the MabEase study (patients with DLBCL) [49]. Grade 3/4 febrile neutropenia was more frequent in the SC arm $(12.5 \%$ vs. $6.9 \%, p=0.0575)$. Injection-site reactions were reported by $5.7 \%$ of patients in the SC arm compared with no patients in the IV arm.

Patients with CLL show a similar pattern. Proportions of patients reporting adverse events of any grade were $96 \%$ for SC and $91 \%$ for IV in the SAWYER trial [48]. The most common grade $\geq 3$ adverse event was neutropenia (56\% SC and 52\% IV); the most common serious adverse event was febrile neutropenia (11\% SC and $4 \%$ IV). ARRs were reported in $44 \%$ of SC and $45 \%$ of IV patients. More patients reported local cutaneous reactions after rituximab SC ( $42 \%$ versus $2 \%$ ); most of these reactions were grade $1-2$.
ARRs were commonly experienced following both IV and SC dosing in an ongoing phase IIIb study (MabCute) investigating the efficacy and safety of rituximab SC maintenance until disease progression in patients with NHL [52]. In this study, all patients receive one cycle of rituximab IV followed by rituximab SC in subsequent cycles of induction and maintenance (Table 1). The overall safety profile was similar to that seen in previous trials, with neutropenia, nausea, and pyrexia the most common adverse events. In total, $28 \%$ of patients experienced an ARR after one dose of rituximab IV, while $41 \%$ of patients had reported an ARR after a median of five cycles of rituximab SC. The phase IIIb MabRella safety study is specifically investigating ARRs following multiple doses of rituximab SC in combination with chemotherapy for the first-line or maintenance treatment of patients with NHL (Table 1) [54]. Preliminary results indicate an overall safety profile in keeping with previous reports, with neutropenia, asthenia, erythema, and pyrexia the most common adverse events. Overall, $22 \%$ of patients experienced an ARR, with erythema (10\%) and injection site erythema (4\%) being the most common.

Reassuringly, adverse event rates have been similar for rituximab IV and SC administration in patients with low, medium, and high BSA $[44,45]$, suggesting that fixed-dose administration does not increase toxicity in low BSA patients, in whom antibody exposure may be greater relative to the exposure after rituximab IV BSA-adjusted dosing. The lack of increased toxicity after greater exposure was expected, as the exposure after BSA-adjusted dosing results in near complete target site saturation, and in that context there is a low probability of surplus rituximab IgG monoclonal antibodies not binding to their target to cause additional toxicity.

Rituximab SC is therefore well tolerated, with an adverse event profile similar to rituximab IV. Data from the post-marketing setting, which included over 34,000 patients exposed to rituximab SC as of September 2016 (data on file), were consistent with clinical trial experience. 


\section{BENEFITS OF SUBCUTANEOUS ADMINISTRATION}

\section{Reduced Treatment Burden for Patients}

The burden of cancer treatment is felt across all demographics and in all countries. By simplifying and shortening rituximab preparation and administration with SC dosing, it was anticipated that rituximab SC would reduce the treatment burden for patients, as has been shown for trastuzumab $[33,55]$. The much shorter preparation and delivery time of rituximab SC versus IV reduces the time required for patients to be present in the clinic, which has implications for resource utilization (see later). In addition, rituximab SC given in combination with other SC or oral chemotherapeutics, or as single-agent maintenance, would eliminate the need for central venous access. The potential for reduction of burden of cancer treatment is considerable, and studies suggest that this is indeed the case, with patients preferring rituximab SC for its convenience and reduced impact on their lives.

In a prospective, randomized, open-label, crossover study investigating patient preference for rituximab SC or IV in patients with previously untreated DLBCL or FL (PrefMab study), $77-84 \%$ of patients expressed a preference for rituximab SC at cycle 8 [Fig. 5; 51]. The most commonly identified reasons for preference for rituximab SC were "requires less time in the clinic," "feels more comfortable during administration," and "feels less emotionally distressing" (Fig. 5). Preference was assessed using a Patient Preference Questionnaire that recorded SC, IV, or no preference and rated preference on a three-point scale, as well as asking patients to report two main reasons for their preference.

Furthermore, rituximab SC was associated with higher scores than rituximab IV on a rituximab-specific treatment satisfaction questionnaire that rated various aspects of treatment on a $0-100$ scale: patient satisfaction (88 vs. 75$)$, impact on activities of daily living (83 vs. 58 ), and convenience ( 83 vs. 58 ). Median administration time per cycle has been shown to be substantially lower for SC than IV dosing: $6 \mathrm{~min}$ versus $170-240 \mathrm{~min}$. Patients participating in
Fig. 5 Findings from the PrefMab study showing an overall patient preference for the SC or IV route of rituximab administration at cycles 6 and 8; $\mathbf{b}$ strength of patient preference for the SC or IV route; $\mathbf{c}$ reasons for patient preference in patients preferring $S C$ administration [51]'. Figure reproduced from Rummel M, Kim TM, Aversa F, et al. Preference for subcutaneous or intravenous administration of rituximab among patients with untreated CD20+ diffuse large B-cell lymphoma or follicular lymphoma: results from a prospective, randomised, open-label, crossover study (PrefMab). Ann Oncol. 2017;28:836-42, by permission of Oxford University Press

the MabCute study expressed similar satisfaction and preference for rituximab SC [56], as did patients participating in the MabEase study [57].

Interestingly, the PrefMab study found that scores for the 'psychologic impact' domain of the rituximab-specific questionnaire were similar for both rituximab SC and IV (88 vs. 80) [51]. On the one hand, the shorter administration times associated with rituximab SC may lead to a lower psychologic impact as a result of spending less time in a clinic attached to an IV line, observing other patients receiving their infusions, and potentially, experiencing adverse events. Conversely, IV administration may increase patient support and wellbeing as a result of the closer supervision and prolonged contact occurring between patients and healthcare professionals during extended clinic visits. Notably, a similar proportion of patients in the SC and IV arms of the MabEase study reported that rituximab administration did not affect the amount of time available for them to talk to a doctor or nurse ( $81 \%$ vs. $82 \%)$, suggesting that the shorter infusion time does not interfere with patients' ability to discuss their illness with a healthcare professional [57].

\section{Improved Resource Utilization}

Numerous studies have investigated the impact of SC administration of rituximab on healthcare resource utilization [48, 57-60]. In time and motion studies, rituximab SC was associated with a reduction in active healthcare professional time spent on the preparation and administration of rituximab, a consequent reduction in human resource-related costs, and a reduction in the 

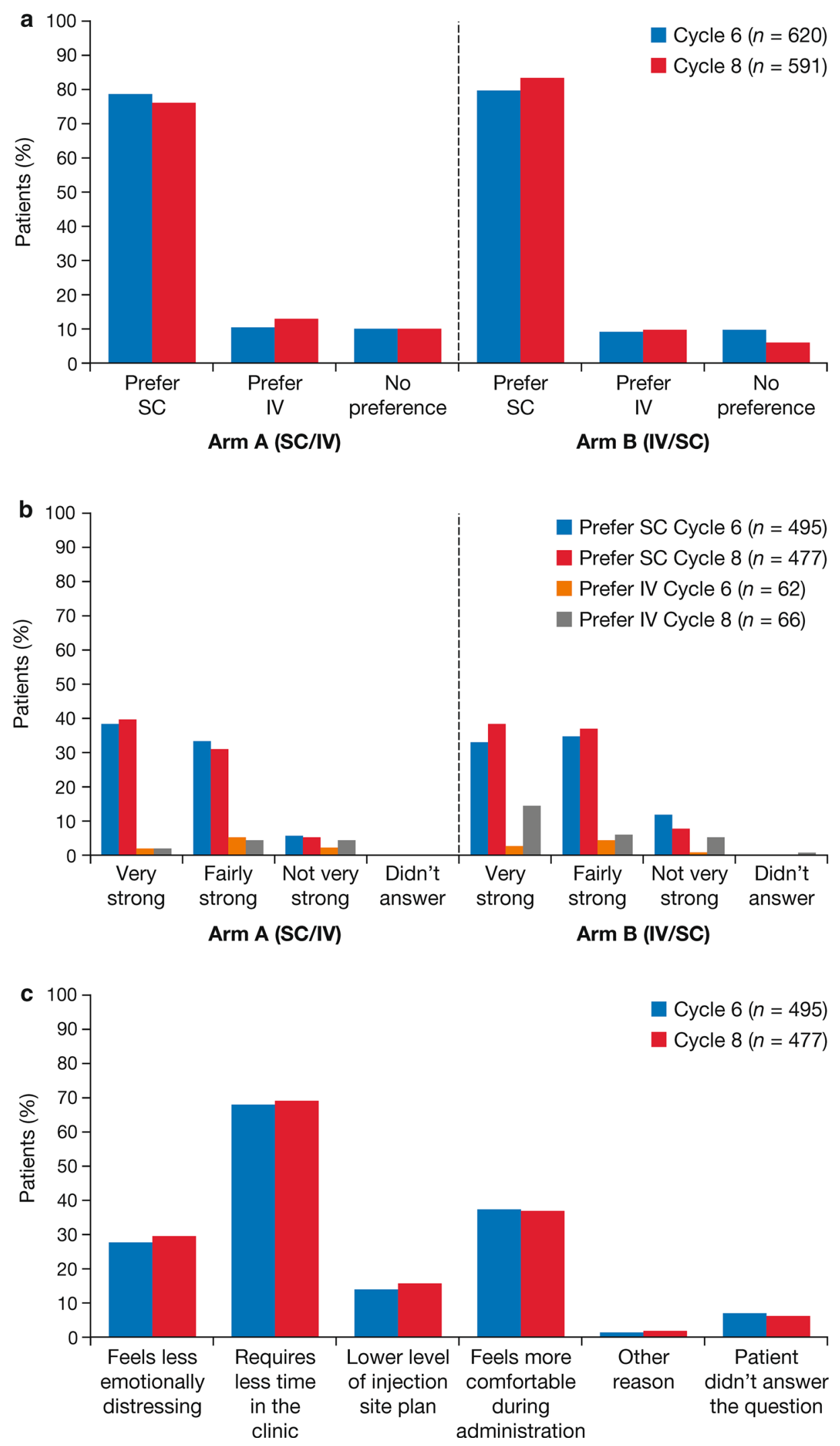
amount of time patients spent in the treatment room compared with rituximab IV [58, 59].

As noted earlier, median administration time for rituximab SC is $6 \mathrm{~min}$ (substantially lower than for rituximab IV: 170-240 min). In the time and motion study that accompanied MabCute, mean active healthcare professional (HCP) time was significantly reduced from 35.0 to $23.7 \mathrm{~min}$ when rituximab was administered SC rather than IV $(-32 \%$ difference; $p<0.0001)$ [59]. The active HCP time was time (stopwatch) actively dedicated by any staff member on prespecified tasks in the treatment room and drug preparation area. In addition, mean patient time spent in the treatment chair was significantly shorter with rituximab SC (67.3 min) compared with rituximab IV (262.1 min; $p<0.0001)$. The authors calculated that an average 3.5 patients could be treated with rituximab SC (first session IV and 10 sessions SC) for every patient treated IV, a finding that has important resource utilization and economic implications. An Italian hospital-based survey reported that rituximab SC resulted in resource and cost savings compared with rituximab IV, including reduced drug wastage [60]. In the SAWYER study, both physicians and nurses reported time savings for SC compared with IV administration, and the majority reported that rituximab SC was more convenient than rituximab IV [48].

These findings suggest that the impact of rituximab SC on healthcare systems worldwide may be substantial. With the therapeutic landscape in hematology evolving toward chemotherapy- and IV-free treatment regimens, administering a key agent like rituximab via a non-IV route would allow for simplified and shortened drug administration and preparation times, leading to reduced treatment burden for patients and improved resource utilization at the treatment facility.

\section{CONCLUSIONS}

The sequential clinical development program utilizing PK and clinical bridging has clearly demonstrated that rituximab SC results in rituximab exposures at least as high as those achieved with rituximab IV. Furthermore, rituximab SC has comparable clinical efficacy and safety to rituximab IV, with the advantage of a reduced treatment burden for patients as well as improved healthcare resource utilization. Rituximab SC is supplied as a ready-to-use formulation, allowing preparation and administration of rituximab therapy within minutes, with no compounding required. Administration of rituximab SC takes considerably less time than rituximab IV, and the fixed- rather than BSA-based dosing potentially reduces the risk of dosing errors and spillage of the IV infusion fluid. For patients with poor venous access, rituximab SC offers an alternative route of administration and may also reduce the risk of catheter-related sepsis if a central venous catheter is no longer required. Increased rates of localized injection site reactions with SC administration have been reported in clinical studies, but these events have been manageable and consistent with expected changes when switching from IV to SC dosing and tend to decrease in frequency and intensity as treatment progresses.

Recognizing the burden of IV infusions on both healthcare systems and patients, the therapeutic landscape in hematology is evolving toward treatment that is chemotherapy-free and based increasingly on non-IV targeted agents [61], which may eliminate the need for central venous access altogether. Several orally administered therapeutics, including ibrutinib, idelalisib, and venetoclax, have recently been approved for use in B-cell malignancies, either as monotherapy or in combination with rituximab or other agents, and many chemotherapy regimens may now also be administered orally [62-66].

Rituximab SC therefore offers a more efficient delivery of rituximab's recognized clinical benefit with less treatment-related burden for patients. The new formulation provides equivalent efficacy and safety to rituximab IV with greater convenience and improved patient satisfaction and time (and potentially cost) saving.

\section{ACKNOWLEDGEMENTS}

Support for third-party writing assistance for this manuscript, provided by Cheryl Wright of 
Gardiner-Caldwell Communications, and article processing charges, were funded by F. Hoffmann-La Roche Ltd., Basel, Switzerland. All named authors meet the International Committee of Medical Journal Editors (ICMJE) criteria for authorship for this manuscript, take responsibility for the integrity of the work as a whole, and have given final approval to the version to be published.

Disclosures. Axel Boehnke is an employee of F. Hoffmann-La Roche Ltd./Genentech Inc. and holds F. Hoffmann-La Roche Ltd. stock. Anjum Dadabhoy is employed by F. Hoffmann-La Roche Ltd. Andrew Davies has received honoraria from F. Hoffmann-La Roche Ltd., Mundipharma, Gilead, Takeda, Janssen, Celgene, and Karyopharma; has performed a consulting/advisory role for F. Hoffmann-La Roche Ltd., Gilead, and Takeda; has received research support from F. Hoffmann-La Roche Ltd., Gilead, Takeda, Bayer, Celgene, GSK, Karyopharma, and Pfizer; and has received support for travel/accommodation from F. Hoffmann-La Roche Ltd. Calude Berge is an employee of F. Hoffmann-La Roche Ltd. Christine McIntyre is employed by, and holds stock from, Roche Products Ltd. Mathias Rummel has received honoraria, has performed a consulting role for F. Hoffmann-La Roche Ltd., and has also received research funding (institutional) from F. Hoffmann-La Roche Ltd. Pieternella Lugtenburg has received sponsorship to attend international meetings, honoraria for attending advisory boards, and research grants from various pharmaceutical companies including Roche, Takeda, Celgene, Servier, Bristol-Myers Squibb, and Gilead. Rodney Smith reports employment with F. Hoffmann-La Roche Ltd. Simon Rule has received research support from Janssen and Celgene; honoraria from Janssen, Celgene, F. Hoffmann-La Roche Ltd., Napp, Pharmacyclics, Gilead, Sunesis, Kite, and TG Therapeutics; and has participated in advisory boards for Janssen, Celgene, F. Hoffmann-La Roche Ltd., Napp, Pharmacyclics, Gilead, Sunesis, Kite, and TG Therapeutics. Xavier Badoux has received honoraria from F. Hoffmann-La Roche Ltd. and Bristol-Meyers Squibb. We thank all investigators as well as patients and their families who have participated in clinical trials establishing the SC route of administration for MabThera/ Rituxan. Special thanks for their contributions to study design, study execution, data analysis, and data interpretation goes to: Melih Aktan, Sarit Assouline, Franco Aversa, Irit Avivi, Wolney-Gois Barreto, Martin Barrett, Henry Bennett, Henriette Berenschot, Alf Bernhardt, Natalia Berthillon, Reda Bouabdallah, Rena Bratke, Mike Brewster, Javier Briones, Wolfram Brugger, Valeria Buccheri, Natalie Cambon, Alicyn Campbell, Enrico Capochiani, Angelo Michele Carella, Olivier Casasnovas, Olivier Catalani, Clarisse Chavanne, Graham Collins, Denise Cotting, Nicola Crosbie, Eva Csinady, Erwin De Cock, Alain Delmer, Natalie Dimier, Mark Dixon, Mark Fisher, George Follows, Klaus Freivogel, Gianluca Gaidano, Diana Gonzalez, Andrew Grigg, Kimberly Hari, Andrew Haynes, Wolfgang Hiddemann, Florence Hourcade-Potelleret, Stacie Hudgens, Kathryn Humphrey, Osman Ilhan, Candice Jamois, Andrea Janikova, Paw Jensen, Kerstin Kellershohn, Nelson Kinnersley, Persefoni Kritikou, Kamel Laribi, Jean-Francois Larouche, Véronique LeBlond, Sirpa Leppa, Congfen Li, Sarah Jayne Liptrott, Armando Lopez-Guillermo, Linda Lundberg, David MacDonald, Lachlan Macgregor, Mika Maekinen, Genevray Magali, Jean Pierre Marolleau, Joerg Mauer, Martino Balkis Meddeb, Maria Mendoza, Santiago Mercadal, Francesco Merli, Dimitri Messeri, Anne-Sophie Michallet, Biljana Mihaljevic, Georgi Mihaylov, Peter Morcos, Carol Moreno, Javier Munoz, Mike Musante, Arnon Nagler, Charles Ngoh, Charles Ngoh, Stuart Osborne, Juliana Pereira, Michael Pfreundschuh, Caterina Plenteda, Chris Pocock, Joao Raposo, Saad Rassam, Francesca Re, Wolfgang Richter, Antonio Rueda, Antonio Salar, Kunal Samanta, Mariana Sandoval, Pakeeza Sayyed, Gabriel Schnetzler, Anna Schuh, Melissa Shaw, Ofer Shpilberg, Noppadol Siritanaratkul, Philippe Solal-Céligny, Markus Stephan-Gueldner, Maris Sugino, Monica Tani, Sunning Tao, Peter Trask, Marek Trneny, Gayane Tumyan, Mehmet Turgut, Ali Unal, Klaas Veenstra, Tim Waterboer, Tom Widenius, Heinz Wiederkehr, Christof Wiesner, Francesco Zaja, and Artem Zharkov. This information is not exhaustive, and we also thank all other 
current and former researchers not mentioned in the list above.

Compliance with Ethics Guidelines. The information reported in this review article is derived from previously conducted studies: this does not include any new studies of human or animal subjects performed by any of the authors. All authors had full access to the information included in this review and take complete responsibility for the integrity of the data discussions.

Data Availability. Data sharing is not applicable to this article as no data sets were generated or analyzed for this publication.

Open Access. This article is distributed under the terms of the Creative Commons Attribution-NonCommercial 4.0 International License (http://creativecommons.org/licenses/ by-nc/4.0/), which permits any noncommercial use, distribution, and reproduction in any medium, provided you give appropriate credit to the original author(s) and the source, provide a link to the Creative Commons license, and indicate if changes were made.

\section{REFERENCES}

1. Reff ME, Carner K, Chambers KS, et al. Depletion of $\mathrm{B}$ cells in vivo by a chimeric mouse human monoclonal antibody to CD20. Blood. 1994;83:435-45.

2. Dreyling M, Ghielmini M, Marcus R, et al. Newly diagnosed and relapsed follicular lymphoma: ESMO Clinical Practice Guidelines. Ann Oncol. 2014;25(Suppl 3):iii76-82.

3. Tilly H, Gomes da Silva M, Vitolo U, et al. Diffuse large B-cell lymphoma (DLBCL): ESMO Clinical Practice Guidelines for diagnosis, treatment and follow-up. ESMO Guidelines Committee. Ann Oncol. 2015;26(Suppl 5):v116-25.

4. Eichhorst B, Robak T, Montserrat E, ESMO Guidelines Committee., et al. Chronic lymphocytic leukaemia: ESMO Clinical Practice Guidelines for diagnosis, treatment and follow-up. Ann Oncol. 2015;26(Suppl 5):v78-84.
5. NCCN Clinical Practice Guidelines in Oncology (NCCN Guidelines ${ }^{\circledR}$ ). Non-Hodgkin lymphoma. $2017 . \quad$ https://www.nccn.org/professionals/ physician_gls/pdf/b-cell.pdf. Accessed 15 June 2017.

6. WHO Model List of Essential Medicines. 19th List (April 2015). http://www.who.int/medicines/ publications/essentialmedicines/en/. Accessed 15 June 2017.

7. MabThera EU Summary of Product Characteristics. Roche Registration Limited. http://www.ema. europa.eu/docs/en_GB/document_library/EPAR_-_ Product_Information/human/000165/WC500025821. pdf. Accessed 15 June 2017.

8. Rituxan United States Prescribing Information. 2010. Genentech Inc. http://www.accessdata.fda. gov/drugsatfda_docs/label/2010/103705s5311lbl. pdf. Accessed 15 June 2017.

9. Kahl BS, Yang DT. Follicular lymphoma: evolving therapeutic strategies. Blood. 2016;127:2055-63.

10. Sehn LH, Gascoyne RD. Diffuse large B-cell lymphoma: optimizing outcome in the context of clinical and biologic heterogeneity. Blood. 2015;125:22-32.

11. Coiffier B, Thieblemont C, Van Den Neste E, et al. Long-term outcome of patients in the LNH-98.5 trial, the first randomized study comparing rituximab-CHOP to standard CHOP chemotherapy in DLBCL patients: a study by the Groupe d'Etudes des Lymphomes de l'Adulte. Blood. 2010;116:2040-5.

12. Jain $\mathrm{N}, \mathrm{O}^{\prime}$ Brien $\mathrm{S}$. Initial treatment of CLL: integrating biology and functional status. Blood. 2015;126:463-70.

13. Shan D, Ledbetter JA, Press OW. Signaling events involved in anti-CD20-induced apoptosis of malignant human B cells. Cancer Immunol Immunother. 2000;48:673-83.

14. Weiner GJ. Rituximab: mechanism of action. Semin Hematol. 2010;47:115-23.

15. Leidi M, Gotti E, Bologna L, et al. M2 macrophages phagocytose rituximab-opsonized leukemic targets more efficiently than M1 cells in vitro. J Immunol. 2009;182:4415-22.

16. Jazirehi AR, Gan X-H, De Vos S, et al. Rituximab (anti-CD20) selectively modifies Bcl-xL and apoptosis protease activating factor-1 (Apaf-1) expression and sensitizes human non-Hodgkin's lymphoma B cell lines to paclitaxel-induced apoptosis. Mol Cancer Ther. 2003;2:1183-93. 
17. Smith MR, Joshi I, Jin FF, Obasaju C. Enhanced efficacy of gemcitabine in combination with anti-CD20 monoclonal antibody against $\mathrm{CD}^{+} 0^{+}$ non-Hodgkin's lymphoma cell lines in vitro and in scid mice. BMC Cancer. 2005;5:103.

18. Chow KU, Sommerlad WD, Boehrer S, et al. Anti-CD20 antibody (IDEC-C2B8, rituximab) enhances efficacy of cytotoxic drugs on neoplastic lymphocytes in vitro: role of cytokines, complement, and caspases. Haematologica. 2002;87:33-43.

19. Marcus R, Imrie K, Solal-Celigny P, et al. Phase III study of R-CVP compared with cyclophosphamide, vincristine, and prednisone alone in patients with previously untreated advanced follicular lymphoma. J Clin Oncol. 2008;26:4579-86.

20. Hallek M, Fischer K, Fingerle-Rowson G, et al. Addition of rituximab to fludarabine and cyclophosphamide in patients with chronic lymphocytic leukaemia: a randomized, open-label, phase 3 trial. Lancet. 2010;376:1164-74.

21. Robak T, Dmoszynska A, Solal-Céligny $\mathrm{P}$, et al. Rituximab plus fludarabine and cyclophosphamide prolongs progression-free survival compared with fludarabine and cyclophosphamide alone in previously treated chronic lymphocytic leukemia. J Clin Oncol. 2010;28:1756-65.

22. Salles G, Seymour JF, Offner F, et al. Rituximab maintenance for 2 years in patients with high tumour burden follicular lymphoma responding to rituximab plus chemotherapy (PRIMA): a phase 3, randomised controlled trial. Lancet. 2011;377:42-51.

23. Keating M, O'Brien S. High-dose rituximab therapy in chronic lymphocytic leukemia. Semin Oncol. 2000;27:86-90.

24. O'Brien SM, Kantarijan H, Thomas DA, et al. Rituximab dose-escalation trial in chronic lymphocytic leukemia. J Clin Oncol. 2001;19:2165-70.

25. Maloney DG, Liles TM, Czerwinski DK, et al. Phase I clinical trial using escalating single-dose infusion of chimeric anti-CD20 monoclonal antibody (IDEC-C2B8) in patients with recurrent B-cell lymphoma. Blood. 1994;84:2457-66.

26. Coiffier B, Haioun C, Ketterer N, et al. Rituximab (anti-CD-20 monoclonal antibody) for the treatment of patients with relapsing or refractory aggressive lymphoma: a multicenter phase II study. Blood. 1998;92:1927-32.

27. Dakhil S, Hermann R, Schreeder MT, et al. Phase III safety study of rituximab administered as a 90-minute infusion in patients with previously untreated diffuse large B-cell and follicular lymphoma. Leuk Lymphoma. 2014;55:2335-40.

28. MacGrath I. Cancer in low and middle income countries. In: Carballo, M. Probrook, editors. Health G20: a briefing on health issues for G20 leaders. Sutton, UK, 2010. p. 58-68. http://www.inctr.org/ fileadmin/user_upload/inctr-admin/58-68\%20MacGra th_2010\%20Final.pdf. Accessed 05 Nov 2016.

29. Peters DH, Garg A, Bloom G, et al. Poverty and access to health care in developing countries. Ann NY Acad Sci. 2008;1136:161-71.

30. Media release. Roche's new time-saving subcutaneous formulation of MabThera approved in Europe for the treatment of common forms of non-Hodgkin Lymphoma. 2017. http://www.roche. com/media/store/releases/med-cor-2014-03-28.htm. Accessed 28 June 2017.

31. Media release: Roche's subcutaneous formulation of MabThera receives approval in Europe for people with chronic lymphocytic leukaemia. 2017. http:// www.roche.com/media/store/releases/med-cor-201605-31.htm. Accessed 28 June 2017.

32. Media release. FDA Approves Genentech's RITUXAN HYCELA, a subcutaneous rituximab coformulated with halozyme ENHANZE technology. 2017. http://www.prnewswire.com/newsreleases/fda-approves-genentechs-rituxan-hycela-asubcutaneous-rituximab-coformulated-with-halozymeenhanze-technology-300478601.html. Accessed 28 June 2017.

33. Shpilberg O, Jackisch C. Subcutaneous administration of rituximab (MabThera) and trastuzumab (Herceptin) using hyaluronidase. $\mathrm{Br} \mathrm{J}$ Cancer. 2013;109:1556-61.

34. Bittner B, Richter WF, Hourcade-Potelleret F, et al. Non-clinical pharmacokinetic/pharmacodynamic and early clinical studies supporting development of a novel subcutaneous formulation for the monoclonal antibody rituximab. Drug Res (Stuttg). 2014;64(11):569-75.

35. Bookbinder LH, Hofer A, Haller MF, et al. A recombinant human enzyme for enhanced interstitial transport of therapeutics. J Control Release. 2006;114:230-41.

36. Wasserman RL, Melamed I, Stein MR, et al. Long-term tolerability, safety, and efficacy of recombinant human hyaluronidase-facilitated subcutaneous infusion of human immunoglobulin for primary immunodeficiency. J Clin Immunol. 2016;36:571-82.

37. Yocum RC, Kennard D, Heiner LS. Assessment and implication of the allergic sensitivity to a single 
dose of recombinant human hyaluronidase injection: a double-blind, placebo-controlled clinical trial. J Infus Nurs. 2007;30:293-9.

38. Bittner B, Richter WF, Hourcade-Potelleret F, et al. Development of a subcutaneous formulation for trastuzumab-nonclinical and clinical bridging approach to the approved intravenous dosing regimen. Arzneimittelforschung. 2012;62(9):401-9.

39. Tobinai K, Igarashi $\mathrm{T}$, Itoh $\mathrm{K}$, et al. Japanese multicenter phase II and pharmacokinetic study of rituximab in relapsed or refractory patients with aggressive B-cell lymphoma. Ann Oncol. 2004;15:821-30.

40. Jäger U, Fridrick M, Zeitlinger $M$, et al. Rituximab serum concentrations during immunochemotherapy of follicular lymphoma correlate with patient gender, bone marrow infiltration and clinical response. Haematologica. 2012;97:1431-8.

41. Golay J, Semenzato G, Rambaldi A, et al. Lessons for the clinic from rituximab pharmacokinetics and pharmacodynamics. mAbs. 2013;5:826-37.

42. Wang DD, Zhang S, Zhao H, Men AY, Parivar K. Fixed dosing versus body size-based dosing of monoclonal antibodies in adult clinical trials. J Clin Pharmacol. 2009;49:1012-24.

43. Mao CP, Brovarney MR, Dabbagh K, et al. Subcutaneous versus intravenous administration of rituximab: pharmacokinetics, CD20 target coverage and B-cell depletion in cynomolgus monkeys. PLoS ONE. 2013;8:e80533.

44. Davies A, Merli F, Mihaljević B, et al. Efficacy and safety of rituximab subcutaneous versus intravenous in first-line follicular lymphoma: the randomised, open-label, phase III SABRINA study. Lancet Haematol. 2017. doi:10.1016/S23523026(17)30078-9 (epub ahead of print).

45. Salar A, Avivi I, Bittner B, et al. Comparison of subcutaneous versus intravenous administration of rituximab as maintenance treatment for follicular lymphoma: results from a two-stage, phase IB study. J Clin Oncol. 2014;32:1782-91.

46. Assouline S, Buccheri V, Delmer A, et al. Pharmacokinetics and safety of subcutaneous rituximab plus fludarabine and cyclophosphamide for patients with chronic lymphocytic leukaemia. Br J Clin Pharmacol. 2015;80:1001-9.

47. Davies A, Merli F, Mihaljevic B, et al. Pharmacokinetics and safety of subcutaneous rituximab in follicular lymphoma (SABRINA): stage 1 analysis of a randomised phase 3 study. Lancet Oncol. 2014;15:343-52.
48. Assouline S, Buccheri V, Delmer A, et al. Pharmacokinetics, safety, and efficacy of subcutaneous versus intravenous rituximab plus chemotherapy as treatment for chronic lymphocytic leukaemia (SAWYER): a phase 1b, open-label, randomised controlled non-inferiority trial. Lancet Haematol. 2016;3:e128-38.

49. Lugtenburg P, Avivi I, Berenschot H, et al. Efficacy and safety of subcutaneous and intravenous rituximab plus cyclophosphamide, doxorubicin, vincristine, and prednisone in first-line diffuse large B-cell lymphoma: the randomized MabEase study. Haematologica. 2017 (in press).

50. Kimby E. Tolerability and safety of rituximab (MabThera). Cancer Treat Rev. 2005;31:456-73.

51. Rummel M, Kim TM, Aversa F, et al. Preference for subcutaneous or intravenous administration of rituximab among patients with untreated $\mathrm{CD}^{+} \mathrm{O}^{+}$ diffuse large B-cell lymphoma or follicular lymphoma: results from a prospective, randomised, open-label, crossover study (PrefMab). Ann Oncol. 2017;28:836-42.

52. Rule S, Briones J, Carella AM, et al. Extending subcutaneous rituximab maintenance therapy from 2 years until progression versus observation in patients with indolent non-Hodgkin's lymphoma: interim safety data from the MABCUTE study. Blood 2013;122. (ASH annual meeting abstracts, abstract 3052).

53. Burrows SH, Akinbobuyi O, Rule S, Crosbie N. Subcutaneous rituximab can be safely administered without pre-medication. Br J Haematol. 2017. doi:10.1111/bjh.14703 (epub ahead of print).

54. Panizo C, Bekadja MA, Meddeb B, et al. Safety of subcutaneous administration of rituximab during the first-line treatment of patients with non-Hodgkin lymphoma: the MabRella study. Haematologica. 2017;102(s2):1-882 (P640).

55. Pivot X, Gligorov J, Müller V, et al. Preference for subcutaneous or intravenous administration of trastuzumab in patients with HER2-positive early breast cancer (PrefHer): an open-label randomised study. Lancet Oncol. 2013;14:962-70.

56. Rule S, Briones J, Smith $\mathrm{R}$, et al. Preference for rituximab subcutaneous (SC) and intravenous (IV) among patients with $\mathrm{CD}_{20}{ }^{+}$non-Hodgkin's lymphoma (NHL) completing the RASQ measure in randomized phase III studies PREFMAB and MABCUTE. Value Health. 2014;17(7):A537.

57. Lugtenburg P, Rueda A, Avivi I, et al. Patient satisfaction with subcutaneous vs intravenous rituximab combined with CHOP for untreated diffuse large B-cell lymphoma: results from the Phase IIIb 
MabEase study. Hematol Oncol. 2013;33(Suppl 1). (abstract S383).

58. Rule S, Collins GP, Samanta K. Subcutaneous vs intravenous rituximab in patients with non-Hodgkin lymphoma: a time and motion study in the United Kingdom. J Med Econ. 2014;17:459-68.

59. De Cock E, Kritikou P, Sandoval M, et al. Time savings with rituximab subcutaneous injection versus rituximab intravenous infusion: a time and motion study in eight countries. PLoS One. 2016;11:e0157957. doi:10.1371/journal.pone. 0157957 (epub ahead of print).

60. Ponzetti C, Canciani M, Farina M, et al. Potential resource and cost saving analysis of subcutaneous versus intravenous administration for rituximab in non-Hodgkin's lymphoma and for trastuzumab in breast cancer in 17 Italian hospitals based on a systematic survey. Clinicoecon Outcomes Res. 2016;8:227-33.

61. Cheson BD. CLL and NHL: the end of chemotherapy? Blood. 2014;123:3368-70.

62. Ibrutinib $140 \mathrm{mg}$ hard capsules. Summary of product characteristics. Janssen-Cilag Limited. Last updated 5 Sept 2016. https://www.medicines.org. uk/emc/medicine/29383. Accessed 05 Nov 2016.
63. Idelalisib $100 \mathrm{mg}$. Summary of product characteristics. Gilead Sciences Limited. Last updated 27 September 2016. https://www.medicines.org.uk/ emc/medicine/29202. Accessed 05 Nov 2016.

64. Venetoclax tablets, for oral use. Prescribing information. AbbVie/Roche Products Limited. Last updated April 2016. http://www.accessdata.fda. gov/drugsatfda_docs/label/2016/208573s000lbl.pdf. Accessed 05 November 2016.

65. Fludarabine oral $10 \mathrm{mg}$ tablet. Summary of product characteristics. Sanofi. Last updated 14 October 2015. http://www.medicines.org.uk/emc/medicine/ 4240/. Accessed 05 Nov 2016.

66. Cyclophosphamide tablets $50 \mathrm{mg}$. Baxter Healthcare. Last updated 01 April 2015. https://www. medicines.org.uk/emc/medicine/30161. Accessed 05 Nov 2016.

67. Davies A, Mihaljevic B, Mercadal S, et al. Longer term efficacy and safety of subcutaneous compared with intravenous rituximab: updated results of the phase 3 SABRINA study. Abstract presented at the American Society of Hematology Annual Meeting 2016, Abstract 1103. 